\title{
Nuwe-Testamentiese perspektiewe op die Sabbat en die Sondag
}

S J Joubert

Departement Bybelkunde Universiteit van Pretoria

\section{ABSTRACT}

New Testament perspectives on the Sabbath and the Sunday

In order to come to terms with New Testament views on the Sabbath and the Sunday, an investigation of Jewish schematizations of time and of the Sabbath in particular, around the first century A.D. is undertaken. This is followed by a discussion of relevant New Testament texts on the Sabbath and the Sunday. Finally, the available information from the New Testament is placed within the interpretative framework of the "Christ event" which inaugurated the eschaton, and which also replaced the strong emphasis on specific holy days within early Christianity. However, the Sunday was probably chosen by some early Christian groups as the most suitable day to commemorate the resurrection of Christ.

Hierdie bydrae het ten doel on bepaalde Nuwe-Testamentiese perspektiewe rakende die vroeë Christene se verstaan van die Sabbat en die Sondag aan die orde te stel. Vanuit die sinoptiese evangelies, Handelinge, die Pauliniese briefkorpus en Openbaring gaan kortliks stilgestaan word by die verband tussen die Sabbat en die Sondag, asook by die aard en inhoude van hierdie dae binne die Nuwe-Testamentiese era. Ten einde hierdie teksgedeeltes vanuit die regte perspektief te besien, word 'n kort oorsig oor die Joodse skematisering van die realiteit en hul gepaardgaande sieninge van die Sabbat eerstens aangebied.

\section{JOODSE BESKOUINGE VAN DIE REALITEIT RONDOM DIE EERSTE EEU}

Indien ons op 'n hoë vlak van abstraksie na die Joodse wêreld rondom die eerste eeu ná Christus kyk, dan blyk dit dat hulle die ganse realiteit in terme van rein en onrein, heilig en onheilig, ingedeel en verstaan het. Nie alleen was God vir hulle die absolute vergestalting van heiligheid nie, maar hulleself was ook 'n heilige volk; dit wil sê, hulle was afgesonder, eenkant geplaas, om God op 'n besondere manier te dien. Hierdie opvatting van heiligheid het tot gevolg gehad dat die Jode die ganse realiteit omraam het 
deur sekere denkbeeldige grense, waarvolgens alles en almal se posisie bepaal is in terme van hulle plek en status, binne die geledere van die heiliges, of daarbuite. Diegene wat aan die nodige godsdienstige vereistes voldoen het, is as heiliges beskou, terwyl alle ander persone en objekte onrein was. Bepaalde reinheidsreëls is daarom ook neergelê om onrein persone uit die gemeenskap van die heiliges weg te hou sodat laasgenoemdes nie "besoedel" sou word nie.

Die Misjna-traktaat, "Kelim", wat uit ongeveer die derde eeu na Christus dateer, berig dat daar binne die geledere van die Joodse volk 'n verdere verdeling van mense gemak is vanaf meer heilig tot minder heilig, naamlik: priesters, leviete, gewone Israeliete, bekeerdes tot die Jodendom, bevryde slawe, priesters wat geskors is, tempelslawe, kinders uit sondige verhoudings en diegene wat deur andere ontman is. Slegs persone vanuit hierdie kategorieë het in beginsel toegang tot die kultus gehad (weliswaar op verskillende vlakke). Terselfdertyd kon ook net mense binne hierdie kategorieë met mekaar trou. Alle ander persone en groepe, soos mense wat met misvormde geslagsorgane gebore is, asook sondaars en heidene, is byvoorbaat as onrein beskou en moes uit hul geledere weggehou word'.

Wat die Joodse kategorisering van ruimte of plek betref, noem die Misjna traktaat "Kelim" die volgende heilige plekke in 'n hiërargiese volgorde, naamlik: Die land Israel, ommuurde stede in Israel, Jerusalem, die tempelberg, die voorhof van vroue in die tempel, die voorhof van Israeliete in die tempel, die area vir die priesters in die tempel, die tempelaltaar, die heilige en die allerheiligste. Ten opsigte van tyd verdeel die Misjna versameling "Moed" die kalenderjaar weer ooreenkomstig 'n dalende rangorde van heiligheid, naamlik: die sabbat, paasfees, die versoendag, die loofhuttefees, ander feesdae, die nuwejaar, vasdae en die purimfees.

Alhoewel bogenoemde gegewens uit die Misjna eers rondom die derde eeu na Christus op skrif gestel is, reflekteer dit tog sekere stereotipe Joodse opvattinge wat waarskynlik ook tydens die Nuwe-Testamentiese era gehandhaaf is. So is die verwysing na die priesters en leviete in "Kelim" ongetwyfeld 'n sinspeling op die heersende situasie in Palestina voor die vernietiging van die Jerusalem in 70 ná Christus toe die tempelkultus nog in swang was. 


\section{DIE SABBAT AS DIE HEILIGSTE DAG OP DIE JOODSE KALENDER}

In lyn met en ter versterking van die Ou-Testamentiese opvattinge oor die sabbat as teken van die verbond tussen God en sy volk, en as die vernaamste dag waarop hierdie verhouding ook gevier moes word, het die sabbatdag 'n sentrale plek binne die Jodendom rondom die Nuwe-Testamentiese era ingeneem. Sonder om in detail op al die opvattinge onder die verskillende Joodse faksies en groepe in die Diaspora en in Palestina rakende die sabbat in te gaan, blyk dit dat van alle Jode verwag is om hierdie dag streng te onderhou². Die vóórchristelike Joodse geskrif Jubileë berig dat selfs God en sy engele die sabbat onderhou het. Volgens hierdie dokument is geen werk op dié dag toegelaat nie, behalwe godsdienstige offers. Seksuele gemeenskap op die sabbat was hiervolgens ook verbode. Oortredings van die sabbatswette was met die dood strafbaar. Die erns waarmee die Jode dan die sabbatdag onderhou het, blyk uit 1 Makkabeërs waar vertel word dat meer as 'n duisend Jode by geleentheid doodgemaak is omdat hulle geweier het om die sabbat oorlog te maak.

Die Misjna-traktaat "Sjabbat" gee aan ons 'n interessante kykie op die Farisaïes-rabbynse opvattinge oor die sabbat. Hiervolgens is mense byvoorbeeld verbied om by die aanbreek van die sabbat (dit wil sê, Vrydagaand met sononder) by 'n lamp te lees (1:3) of brood in ' $n$ oond te plaas $(1: 10)$. Op die sabbat is mense ook nie toegelaat om 'n lamp uit te doof met die doel om olie of die lamppit te spaar nie, vanweë die moontlikheid dat hulle in dié proses houtskool kon maak (2:5). Dit was ook verbode om twee briewe op die sabbat te skryf (12:3), om meer as twee drade te weef $(13: 1)$, om asyn te suig om tandpyn te weer (14:4), om koue water oor 'n ontwrigte hand of voet te gooi $(22: 6)$, om werkers te huur (23:3), en dies meer.

Tesame met alles wat verbode was op die sabbat, vermeld die traktaat "Sjabbat" ook wat mense wel op dié dag kon doen. So is mense verbied om die strooi op hul beddens op die sabbat met hul hande te verskuif, maar hulle kon dit wel met hulle lywe doen (20:5). Hulle kon ook insekte, wurms en slakke (dit wil sê, onrein diere) doodmak (14:1), genoeg kos vir die volgende drie maaltye bêre indien hul huis op dié dag aan die brand sou raak (16:2) en wyn vir drie maaltye vanuit 'n gebreekte houer in ' $n$ ander op die sabbat oorplaas (22:1). 


\section{DIE SABBAT IN DIE NUWE TESTAMENT: ENKELE PERSPEKTIEWE}

\subsection{Jesus en die sabbat}

Die evangelies bied geen sistematiese perspektief op Jesus se sieninge van die sabbat nie. Trouens, daar kom verbasend min gegewens hieroor in die evangelies voor, wat in elk geval nog binne die eiesoortige raamwerke van die verskillende evangelies self verstaan moet word.

Uit die karige verwysings vanuit die vier evangelies blyk dit ten minste dan dat Jesus nie afwysend jeens die formele onderhouding van die Joodse kalender in die algemeen en die sabbat in die besonder gestaan het nie. Volgens Johannes $(2: 13 ; 6: 4 ; 7: 10 ; 11: 55)$ het Jesus byvoorbeeld drie maal vir die viering van die paasfees en een keer vir die viering van die huttefees na Jerusalem toe opgegaan. Volgens Lukas 4:16 het Hy ook op die sabbatdag na die sinagoge toe gegaan, netsoos wat alle godvresende Jode in hierdie tyd gedoen het ( $\mathrm{vgl}$ ook Hand 13:14; 16:13). In Markus 1:21 word berig dat Jesus ook in Kapernaum op die sabbatdag mense in die sinagoge onderrig het. Die vraag na die inhoudelike betekenis wat Jesus aan die sabbat geheg het, is egter 'n ander saak. In hierdie verband bied die strydgesprek tussen Hom en die Fariseërs rakende die viering van die sabbat, asook sy genesingswonder net hierna op die sabbatdag (Mark 2:23$3: 6)$, 'n paar belangrike rigtingwysers aan ons.

\subsubsection{Die Seun van God is groter as die sabbat}

Volgens Markus heg Jesus nie dieselfde betekenis aan die skematisering van die realiteit (in terme van heilige en onheilige mense, tyd en gebruike) as die religieuse leiers van die Jode nie. Hy raak byvoorbeeld aan mens wat kulties onrein is, soos melaatses $(1: 40-44)$, 'n vrou wat bloedvloeiing het en aan dooies $(5: 21-43)$, Hy assosieer vrylik met sondaars, soos tollenaars (2:13-17) en 'n heidense vrou (7:24-30). Jesus verwerp ook die reinheidsreëls rondom maaltye (7:1-23) en verbreek die Joodse halaka rondom die kategorisering van tyd deur byvoorbeeld nie die voorgeskrewe vastye te onderhou nie $(2: 18-22)$, op die sabbat duiwels uit te dryf $(1: 21$ $28)$, sy dissipels toe te laat om op dié dag koringare te pluk (2:23-28) en ook 'n sieke te genees $(3: 1-6)$.

In die dispuut tussen Jesus en die Fariseërs rakende die sabbat in Markus 2 maak Hy dit duidelik dat $\mathrm{Hy}$ die Kurios oor die sabbat is (verse 27-28); dit is 'n dag wat volgens Hom tot voordeel van die mens gemaak is 
en nie andersom nie. Die totale gerigtheid van die sabbat word met hierdie uitspraak verander. Waar hierdie dag vir die Joodse religieuse leiers 'n opsigselfstaande grootheid is wat mense se bestaan informeer en rig, word dit nou deur Jesus in diens van mense gestel. Die sabbat is ten minste nou 'n dag wat 'n besondere geleentheid tot dienslewering aan ander mense bied. Die fokus verskuif dus weg van die sabbatdag as sodanig na mense aan wie op hierdie dag, en inderdaad ook op alle ander dae, goed gedoen moet word.

Alhoewel Jesus nie met die uitspraak in Markus 2:27-28 die sabbatdag as sodanig afskaf nie, neem genoemde uitspraak 'n belangrike plek in binne die raamwerk van sy nuwe gestaltegewing aan die realiteit ${ }^{3}$. Markus illustreer naamlik in die omringende perikope vanaf 1:15 hoedat Jesus die koninkryk van God met krag laat aanbreek. In hierdie nuwe eskatologiese era, waartydens nuwe wyn in nuwe wynsakke gegooi word (2:22), geld splinternuwe waardes en norme. Dit gaan naamlik nou oor 'n nuwe lewenswyse van dissipelskap $(3: 31-35 ; 8: 34-38)$ wat verband hou met die onvoorwaardelike navolging van Jesus en met onbaatsugtige dade van naasteliefde. Die onderhouding van heilige dae en tye is ondergeskik hieraan, soos wat Jesus self illustreer met sy genesing van die verlamde op die sabbatdag. As Seun van God en as Kurios het Hy naamlik die volmag om die Joodse sabbatsgebooie te verbreek wat indruis teen die eie aard van hierdie nuwe messiaanse tydsbedeling.

Matteus bied in sy parallelteks rakende die sabbatkontrovers (12:114) ook 'n belangrike teologiese begronding ter verduideliking van Jesus se oortreding van die Joodse halaka. Volgens hom is Jesus die langverwagte Messias van Israel wat verhewe is bo die heiligste simbole van Israel, naamlik die tempel, die profete en die konings. Daarom kan Matteus Jesus se optrede op die sabbat regverdig met sy uitspraak dat $\mathrm{Hy}$ groter is as die heiligste plek op aarde, naamlik die tempel (12:6). Hy is ook groter as Jona (12:41) en Salomo (12:42). Om hierdie rede kan Hy sy dissipels toelaat om hulle hongerpyne op die sabbat te stil, aangesien hierdie dag nou gekenmerk moet word deur dade van barmhartigheid jeens ander mense (12:6-8), en nie met die nakoming van slaafse reëls nie.

\subsection{Paulus en die sabbatdag}

Uiteraard is dit riskant om binne die bestek van 'n paragraaf of twee te poog om Paulus se sieninge oor 'n saak soos die sabbat onder woorde te bring. Die kompleksiteit van sy teologiese denke maak dat enige poging van hierdie aard in eensydighede of in oorvereenvoudigings kan verval. 
Met inagneming van hierdie gevare gaan ons slegs 'n paar kantlynopmerkings rondom Paulus se skematisering van die werklikheid waag wat geensins aanspraak op volledigheid maak nie.

\subsubsection{Die lokus van heiligheid verskuif}

Paulus was deeglik op hoogte met die algemene Joodse opvattinge oor heilige plekke, mense en tyd. Hy verwys byvoorbeeld in Filippense 3 en in 2 Korintiërs 11 na sy eie hoë status binne Joodse kringe in die tyd voor sy bekering. Na sy ontmoeting met die opgestane Christus vind daar egter 'n drastiese verandering aan sy eie denke rondom die heersende Joodse kategoriserings van die werklikheid plaas ${ }^{4}$. Kortliks saamgevat, kom dit daarop neer dat die lokus van heiligheid in terme van mense vir hom verskuif vanaf die Joodse volk na alle gelowiges, Jode en nie-Jode. Diegene wat naamlik nou in Christus is, is die uitverkore kinders van God, afgesien van

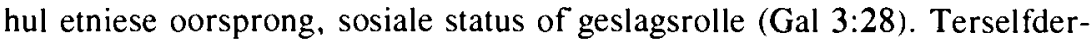
tyd verskuif die lokus van heiligheid in terme van plek nou ook weg van die tempel in Jerusalem na "heilige mense". Alle gelowiges is sodoende nou tempels van die Heilige Gees (1 Kor 3:16;6:19). Wat die viering van spesifieke heilige dae en tye betref, vind daar ook volgens Paulus ' verskuiwing plaas deurdat die aard van die tyd as sodanig verander. Met die kruisgebeure neem die ganse realiteit 'n eskatologiese dimensie aan. In die woorde van 2 Korintiërs 5:17 het alles nou nuut geword. Christene leef daarom in die tydsbedeling van Christus se heerskappy waarbinne hulle alles en almal in 'n nuwe lig moet besien's. Ooreenkomstig die tipiese antieke mediterreense opvattinge oor tyd koppel Paulus dit nou eerder aan bepaalde gebeure en persone, oftewel, aan die kruisgebeure en aan Christus wat nou die ganse kosmos met sy teenwoordigheid vul ${ }^{6}$.

\subsubsection{Konkrete probleme rondom die viering van heilige dae binne die Pauliniese gemeenskappe}

\subsubsection{Galasiërs 4:10-11}

As deel van sy argument rondom die verhouding tussen geloof, die beloftes en die wet van God berispe Paulus die Galasiërs (3:1-4:11) onder andere omdat hulle steeds die Joodse feeskalender navolg. Hy sluit hierdie afdeling in 4:9 af met die vraag waarom hulle nou terugkrabbel na die swak en geringe "elemente" (die stoigeia), en weer daaraan verslaaf raak7. In verse 10-11 betrek Paulus dan ook die Joodse feeskalender in sy 
argument as hy, sonder om spesifieke Joodse heilige tye by die naam te noem, verwys na die gebruik om bepaalde dae (moontlik die sabbat, vasdae en amptelike feesdae soos die paasfees), maande (nuwemaansfees) en jare (die sabbatsjaar en jubeljaar) te onderhou. Enige pogings dus om Christene te verplig om by uitgediende godsdienstige kategoriserings van die tyd in te val, soos wat blykbaar gebeur het sedert die aankoms die Judaïstiese opponente van Paulus in Galasië, druis vir hom in teen die grein van die nuwe bedeling wat met die kruisgebeure aangebreek het.

\subsubsection{Romeine 14:5-6}

In Paulus se bespreking van die problematiek rakende die sogenaamde "sterkes en die swakkes" (Rom 14:1-15:13), word in 14:5-6 na mense verwys wat sekere dae as heiliger as andere beskou. Hy stel dan dat die onderhouding van heilige dae (waarby die sabbat na alle waarskynlikheid ook ingesluit is) ' $n$ persoonlike saak is waaroor gelowiges mekaar nie moet veroordeel nie. Elkeen moet in hierdie verband na goeddunke handel, mits dit alles tot eer van God geskied. Diegene wat dan wel verkies om bepaalde heilige dae te onderhou, moet dit vir die Here doen, terwyl die persone wat verkies om alle dae gelykwaardig te beskou, dit ook vir die Here moet doen. Paulus verval dus nie in kasuïstiek ter oplossing van hierdie problematiek wat blykbaar rondom die onderhouding van bepaalde Joodse seremoniële wette onder die gelowiges in Rome ontstaan het nie. Aan die hand van die beginsel dat hulle alles tot verheerliking van God, asook met liefde en begrip vir mekaar se standpunte moet doen, verwag Paulus dus verdraagsaamheid onder die gelowiges.

\subsubsection{Kolossense 2:16-23}

In hierdie gedeelte spreek Paulus hom skerp uit teen die vreemde kultiese (verse 16-19) en asketiese gedrag (verse 20-23) van sekere gelowiges in Kolosse. Hy verset hom onder andere teen hulle onderhouding van heilige dae soos sabbatte en nuwemaansfeeste (vers 16). Binne hierdie Christelike gemeenskap, waar navolging van Joodse rituele en godsdienstige gebruike waarskynlik as maniere gesien is om in kontak met God te kom, benadruk Paulus nou dat Christus die enigste nuwe werklikheid is $(2: 17)^{8}$. Hy omvat die ganse realiteit; daarom hoef mense nie meer allerlei rituele na te volg, soos om heilige dae te hou en engele te vereer nie (vers 18). Gelowiges het immers saam met Christus gesterf en is nou dood vir al die elemente (stoigeia) van hierdie wêreld (vers 20). 
Uit bogenoemde drie tekste, wat vanuit verskillende invalshoeke op die Joodse feeskalender inspeel, blyk dit dat Paulus nie die viering van die sabbat, of enige ander Joodse heilige tye voorgestaan of aktief aangemoedig het nie. Vanweë sy nadruk op die transformerende impak van die kruisgebeure op die ganse werklikheid, is hierdie sake vir hom van minder belang. Al wat nou saakmaak is Christus. Hy herdefinieër en omvat immers die ganse werklikheid, insluitend die tyd. Binne hierdie eskatologiese tyd moet die fokus daarom volgens Paulus op Christus val, nie op die onderhouding van bepaalde tye en dae nie. Waar ("swak") gelowiges egter, vanweë gebrekkige insig in die nuwe aard van die tyd, verkies om steeds bepaalde heilige tye te onderhou, moet hulle dit ter wille van God doen, en nie ter wille van een of ander godsdienstige tradisie nie.

\section{DIE SONDAG IN DIE NUWE TESTAMENT}

Het die vroeë Christene die sabbat met die Sondag vervang, soos wat vele mense vandag meen? Helaas bied die Nuwe Testament geen direkte antwoorde op hierdie vraag nie. Trouens, volgens die beskikbare gegewens lyk dit asof daar nie volkome eenstemmigheid onder die eerste Christene rondom hul skematiserings van die realiteit, en met name hul opvattings oor heilige tye, bestaan het nie. Onder die leiding van Jakobus het die Jerusalemgemeente byvoorbeeld nog sekere Joodse gebruike getrou nagevolg, soos gereelde besoeke aan die tempel (Hand 2:46; 3:1), die Nasareër geloftes (Hand 21:17-26) en waarskynlik ook die onderhouding van die sabbat. Vele Joodse bekeerlinge tot die Christendom binne die Diaspora het ook nog vir 'n geruime tyd die byeenkomste in die sinagoges bygewoon (Hand 13:42-44; 17:1). Aan die ander kant het die sending van Paulus onder die heidene tot gevolg gehad dat nuwe sieninge rakende die funksionering van die wet en Joodse gebruike binne die vroeë kerk posgevat het. Die sogenaamde "apostel-konvent" in Jerusalem (Gal 2), waar besluit is dat die besnydenis nie 'n verpligte toelatingsritueel was wat mense moes deurloop om deel van die kerk te kon word nie, het in hierdie verband 'n beslissende rol gespeel in die afwysing van 'n wettiese lewensstyl in die (grootste gedeelte van) die vroeë kerk. Binne die Pauliniese gemeentes het dit onder andere geïmpliseer dat gelowiges nie verplig was om die Joodse skematiserings van mense, plek en tyd (en dus ook die onderhouding van die sabbat) na te volg nie.

In die lig van pasgenoemde gevolgtrekking is dit 'n vraag of 'n beduidende aantal vroeë Christene tog nie, aan die hand van hul nuwe skematiserings van die realiteit rondom die kruisgebeure, die Sondag as 
nuwe heilige dag in die plek van die sabbat daargestel het nie? In hierdie verband moet ons kortliks na die verskillende Nuwe-Testamentiese tekste rondom die Sondag kyk voordat ons enige afleidings in hierdie verband kan maak.

\subsection{Nuwe-Testamentiese gegewens rakende die viering van die Sondag}

\subsubsection{Handelinge 20:7-12}

In Handelinge 20:7-12 lees ons van Paulus se optrede in Troas tydens 'n byeenkoms van gelowiges op die eerste dag van die week (he mia ton sabbatton). Tydens hierdie geleentheid het hulle ook saam 'n gemeenskaplike maaltyd geëet (klasai arton) en na prediking geluister'. Die vraag is natuurlik of hierdie gemeenskaplike maaltye in die vroeë kerk net op Sondae plaasgevind het? Vanuit Handelinge 2:46 lyk dit asof hierdie maaltye ten minste binne die Jerusalemgemeente op 'n daaglikse basis plaasgevind het. Die res van die Nuwe Testament verskaf ongelukkig geen verdere aanduidings rakende die frekwensie hiervan nie.

Dit is moeilik om konkrete afleidings rakende enige vorm van Sondagviering te mak vanuit die feit dat Lukas vermeld dat die byeenkoms in Troas op die eerste dag van die week plaasgevind het. Dit is eie aan hom om sekere biografiese detail aangaande Paulus se reise te verskaf (hoe lank hy op plekke vertoef, wanneer hy vertrek, ensovoorts). Aan die ander kant is dit egter ook waar dat Lukas nooit spesifıeke dae in Handelinge vermeld nie, tensy dit verband hou met feesdae. Daarom kan ons nie sy verwysing na die "eerste dag van die week" oorhaastig as net maar nog 'n stukkie biografiese detail afmaak nie. Verder is die kombinasie van drie tegniese begrippe wat spoedig in die vroeë kerk gebruik is om die gemeentelike samekomste mee te verwoord, soos die gemeentelike "byeenkoms", "die eerste dag", en "die breek van die brood" (vgl ook 1 Kor 11:20; Didage 14:1), net te opvallend om te ignoreer ${ }^{10}$. Ons sou daarom die vermoede kon waag dat die eerste dag van die week deur die gelowiges in Troas en deur Paulus as die mees geskikte tyd beskou is om byeen te kom. Teen die tyd dat Lukas Handelinge skryf (waarskynlik rondom die tagtigerjare van die eerste eeu) is hierdie gebruik van die Christene om op die eerste dag van die week "amptelik" byeen te kom, waarskynlik in sommige plekke 'n gevestigde gebruik sodat hy nie nodig gehad het om dit verder aan sy lesers te verduidelik nie. 


\subsubsection{Korintiërs 16:1-4}

In hierdie teksgedeelte, waar Paulus verwys na die insameling van die geld vir die verarmde Jerusalemgemeente, reël hy dat gemeente in Korinte hul geld vir hierdie projek op die eerste dag van die week (he mia ton sabbaton) opsy moet sit. Omdat hier geen sprake is dat dit tydens 'n gemeentelike byeenkoms moes plaasvind nie, is dit moeilik om afleidings oor enige vorm van Sondagviering vanuit 1 Korintiërs 16 te maak. Trouens, dit kan selfs wees dat Paulus hier vir Joodse Christene in Korinte, wat steeds die sabbat onderhou het, probeer tegemoet kom deur te reël dat hulle nie op die sabbatdag geld hoef te hanteer nie (wat 'n verbreking van die sabbatswette kon impliseer ${ }^{11}$ ). Aan die ander kant egter is die nadruk op die Sondag as die dag waarop sekere georganiseerde religieuse handelinge moet plaasvind, dalk nie toevallig nie, veral nie binne 'n gedeelte waar Paulus in elk geval baie spesifieke voorskrifte rondom die inrigting van die kollekte vir Jerusalem gee nie. Waarom dan nie maar op enige ander dag nie?

Die feit dat geld vir die armes in Jerusalem juis op die eerste dag opsy gesit moes word, omvat moontlik meer as net 'n noodtoegewing aan Joodse Christene, wat in elk geval in die minderheid binne die Korintiërgemeente was. Dit hou waarskynlik verband met die verstaan van hierdie dag as die nuwe feesdag binne die geledere van die Pauliniese gemeenskappe waartydens die gemeenskaplike maaltyd ook gevier is.

\subsubsection{Openbaring 1:10}

In Openbaring 1:10 word van die kuriake hemera gepraat. Vanuit vroegkerklike- en apokriewe geskrifte soos Justinus die Martelaar, die Didage, die Handelinge van Petrus en die Handelinge van Paulus, weet ons dat dit op die dag direk na die sabbat, dit wil sê die Sondag, dui12. Dit is juis op hierdie dag dat die skrywer van die Openbaringboek in gebed verkeer, en waarop hy sy groot visioen van die opgestane Here ontvang ${ }^{13}$.

Die skrywer se gebruik van die term "dag van die Here" om die Sondag hier in Openbaring 1:10 mee te tipeer, dui waarskynlik daarop dat 'n bepaalde identiteit en kwaliteit aan dié dag toegeken is binne kringe waar die Johannese geskrifte die lig gesien het. Op grond van die impak van Jesus se opstanding uit die dood op die eerste dag (vgl par 4.1.4), wil dit voorkom asof die Sondag dié dag geword het waarop die gemeentes in Klein-Asië Jesus se heerskappy oor die wêreld feestelik saam gevier het. 


\subsubsection{Jesus se opstanding uit die dood}

Jesus se opstanding op die eerste dag van die week (Matt 2:1; Mark 16:2; Luk 24:1) en sy verskynings aan sy dissipels - waarvan een op 'n Sondag plaasvind (Joh 20:26), bied geen direkte inligting (of bevel) in verband met die instelling van die Sondag as nuwe feesdag in die plek van die sabbat nie. Tog het dit na alle waarskynlikheid 'n sterk invloed uitgeoefen op die groot klem wat die vroeë Christene (veral vanaf die tweede eeu) op weeklikse samekomste op Sondae geplaas het. Vandaar dan die gebruik van die uitdrukking "dag van die Here" in Openbaring.

Die Sondag was die mees logiese dag van die week vir Christelike samekomste, aangesien dit die navolgers van Jesus onderskei het van Jode wat weer op die sabbat byeengekom het. Hierdie byeenkomste, wat soggens voor werk of in die aande na werk plaasgevind het, is gekenmerk deur die viering van Christus se opstanding uit die dood, sy heerskappy oor die ganse kosmos en die geskiedenis (Openbaring) en die nuwe sabbatsrus wat Hy vir sy kerk gebring het (Hebreërs). Die Sondag was dus 'n dag waarop die Christene se identiteit duidelik uitgestippel is teenoor ander godsdienste en groepe, en waarop hulle die oorwinning van Christus feestelik saam herdenk het.

\section{SAMEVATTENDE KONKLUSIES}

Die Nuwe-Testamentiese geskrifte bied geen eksplisiete antwoorde op ons vrae rondom die aard van die Sondag en die verhouding tussen die Sondag en die sabbat nie, soos byvoorbeeld of eersgenoemde dag die sabbat vervang het as ' $n$ nuwe heilige dag en of die betekenis van die sabbat net so op die Sondag oorgedra is. Helaas het baie teologiese diskussies rondom die Sondag/sabbat in die verlede op hierdie punt gestuit.

'n letwat ander invalshoek tot die Sondag/sabbat problematiek, wat deur die loop van hierdie artikel gevolg is, omvat meer as net 'n bespreking van alle moontlike tekste wat met hierdie saak verband hou. Dit behels naamlik dat daar vanuit sosiaal-wetenskaplike perspektief gevra word na die werklikheidskonstruksies van bepaalde groepe en gemeenskappe. Indien ons byvoorbeeld sou kon vasstel hoe sekere gemeenskappe hul realiteit in terme van heilig en onheilig, of rein en onrein konstrueer, dan kan ons ook bepaal watter waardes hulle onder ander toeken aan tyd, plek, ruimte, objekte en mense.

In hierdie verband het ons dan op 'n hoë vlak van veralgemening gekyk na die Joodse skematiserings van die realiteit rondom die Nuwe- 
Testamentiese era, en met name na hul fokus op die sabbat as die heiligste dag op die kalender. Hierteenoor het ons ook gekyk na die oorkoepelende werklikheidskonstruksies van die vroeë Christene vir wie die fokus deurentyd op die Christusgebeure val. Christus se sterwe en opstanding vorm naamlik die hart van die Nuwe-Testamentiese leefwêreld. Dit is die oriënteringspunt vanwaar die ganse realiteit, insluitend mense, plek en tyd, beoordeel word. Daarom moet ons nie verwag dat die Nuwe Testament te veel te sê sal hê oor 'n saak soos Sondagviering nie, aangesien dit nie in die middelpunt van hulle nuwe werklikheidsbeskouinge gestaan het nie.

Die Nuwe-Testamentiese heroriëntasie van die realiteit neem Jesus se aardse optrede as verwysingspunt. Volgens die beskikbare gegewens in die evangelies, het Hyself nooit enige vorm van sabbatsonderhouding verpligtend gemaak nie. Trouens, uit sy messiaanse uitsprake en optrede blyk dit dat Hy 'n nuwe werklikheid, te wete "die koninkryk van God" daargestel het. Hierbinne verskuif die fokus vanaf die uiterlike onderhouding van heilige dae na onvoorwaardelike diens aan God en aan andere.

Leiersfigure binne die vroeë kerk, soos Paulus, het selfs so ver gegaan om die sabbat as heilige dag oorbodig te verklaar vanweë hul nuwe verstaan van die Christusgebeure. Alhoewel Joodse Christene waarskynlik vir 'n geruime tyd nog die sabbatdag gevier het, het die NuweTestamentiese skrywers aanvaar dat die ganse realiteit, en daarmee saam die aard van die tyd, radikaal verander het met Christus se koms. Alles het nou nuut geword. Die era van die sabbatsrus vir God se nuwe volk het nou aangebreek, wat nie langer afhanklik is van die onderhouding van bepaalde heilige kalendertye nie.

Alhoewel die vroeë Christene kennelik nie van die Sondag 'n nuwe sabbat gemaak het nie, kan ons aanvaar dat sommige van hulle wel georganiseerd op hierdie dag byeengekom het, sodat ons wel spore van 'n tipe "Sondagviering" in die Nuwe Testament aantref, al is dit ook baie vaag. Handelinge 20:7; 1 Korintiërs 16:2 en Openbaring 1:10 weerspieël moontlik die gebruik in sekere vroeg-Christelike gemeenskappe om wel op Sondae saam te kom. Alhoewel die Nuwe Testament dit nie eksplisiet uitspel nie, het Jesus se opstanding uit die dood tog 'n belangrike rol gespeel in die daarstelling van 'n tipe feesdag waarop die vroeë Christene hul Heer se opstanding gesamentlik kon vier en hulleself kon afgrens van ander groepe wat ander heilige kalendertye onderhou het.

Ten slotte: vanuit die tweede eeuse Christelike geskrifte weet ons dat die Sondag toenemend belangrik geword het in die vroeë kerk. Justinus die Martelaar $(150 \mathrm{nC})$ skryf byvoorbeeld in sy Eerste Apologie dat die 
Christene op die Sondag byeenkom omdat Christus op hierdie dag uit die dood opgestaan het, maar ook omdat God die wêreld op die eerste dag geskep het. Op Sondae het gelowiges volgens Justinus uit die profete en die apostels saamgelees, 'n kort preek aangehoor, saam gebid en dan saam die nagmaal gevier. Hierdie byeenkomste het gewoonlik voor sonop en/of na sononder plaasgevind aangesien die vroeë gelowiges steeds op Sondae moes werk. Eers vanaf die vierdie eeu, nadat die Christendom die amptelike godsdiens van die Romeinse Ryk geword het, het die Sondag 'n amptelike rusdag geword. Dit is ook vanaf die vierde eeu dat die Sondag algaande binne vele kerklike kringe die karakter van 'n sabbat begin aangeneem het.

\section{NOTAS:}

1 B J Malina, The New Testament world: Insights from cultural anthropology, Louisville 1993, 159-162.

2 C Rowland, "A summary of Sabbath observance in Judaism at the beginning of the christian era", in: D A Carson (ed), From Sabbath to Lord's day. A biblical and historical investigation, Grand Rapids 1982, 44-45.

3 J Gnilka, Jesus von Nazaret. Botschaft und Geschichte, Freiburg 1990, 222.

4 Vergelyk J Neyrey, Paul, in other words. A cultural reading of his letters, Louisville 1990.

$5 \quad$ Aldus C K Barrett, Paul. An introduction to his thought, London 1994, 99-103. Kyk ook B Witherington, Paul's narrative thought world: The tapesiry of tragedy and triumph, Louisville 1994, 234-235 en ietwat anders, J Becker, Paulus. Der Apostel der Völker, Tubingen 1992, 110-111.

6 In sake antieke tydsbeskouinge, vergelyk B Malina, S J Joubert \& J G van der Watt, A time travel to the world of Jesus. A modern reflection of ancient Judea, Halfway House 1996, 91-106.

7 Hierdie stoigeia kan volgens A Oepke Der Brief des Paulus an die Galater, Berlin 1973,139, op geestelike magte dui wat "als Planetengeister den Kalender regeln".

8 E Schweizer, Der Bricf an die Kolosser, Zürich 1976, 119-120.

9 R Riesner, "Synagogues in Jerusalem", in: R Bauckham (ed), The book of Acts in its first century setting. Book 4: The book of Acts in its Palestinian setting. Grand Rapids 1995, 206. 
10 M M B Turner. "The Sabbath. Sunday, and the Law in I uke/Acts", in: Carson (ed), $a w, 132$.

11 Vergelyk W F Orr \& J A Walther, I Corimhiams. A "ww Iramslation. Introduction with a study of the life of Paul, notes, and commentun, New York 1976. 57.

12 R J Bauckham. "The Lord's Day", in: Carson (ed), a w, 221-250.

13 Alhoewel ons nie met presiese sekerheid kan sê wanneer hierdie grootse apokaliptiese werk op skrif gestel is nie, kan ons aanvaar dat dit waarskynlik rondom die negentigerjare van die eerste eeu geskryf is aan Christene in KleinAsië. Vergelyk byvoorbeeld J A du Rand, Johammine perspectives. Introduction to the Johamino writings - Part I, Halfway House 1991, 228-234. 